\title{
El juego motor del marro: una indagación acerca de sus raíces pedagógicas
}

\author{
The Game Prisoner's Bar: A Research \\ on Their Educational Backgrounds
}

\author{
Jordi Brasó Rius ${ }^{1}$ \\ Universidad de Barcelona \\ Xavier Torrebadella Flix ${ }^{2}$ \\ Universidad Autónoma de Barcelona
}

\section{RESUMEN}

Desde muy antiguo el juego motor del marro ha permanecido en el depósito cultural de la civilización occidental. Sin embargo, las raíces antropológicas, sociológicas y pedagógicas de este juego han sido escasamente investigadas. A partir de la indagación cultural de sus orígenes nos adentramos en averiguar el por qué esta práctica físico-recreativa ha permanecido durante tantos siglos prácticamente inalterada. El estudio parte de un enfoque histórico-genealógico y fenomenológico interdisciplinar (antropología, sociología y pedagogía) sustentado por una variada revisión documental de fuentes primarias. Los resultados nos llevan a sostener que en la lógica interna del juego del marro subyacen los códigos socializantes de la pedagogía contemporánea, por lo que su duradera presencia viene a garantizar la teoría del "proceso de civilización" de Occidente. Esta interpretación contribuye también a valorar una comprensión fenomenológica en la historia de los juegos corporales y el rol que desempeñan en la sociedad.

Palabras clave: Historia de la educación física; Juego del marro; Historia del deporte; Juegos tradicionales.

\section{SUMMARY}

The collaborative game of Prisoner's Base (also called Prisoner's Bars) has formed part of the cultural repository of Western civilisation from very remote times. Nevertheless, the anthropological, sociological and educational roots of this game have been only very slightly researched. Starting with a cultural assessment of its origins, we attempt to ascertain exactly why this physical-recreational game has remained practically unaltered over the centuries. The study adopts an approach that covers historical-genealogical and interdisciplinary phenomenological aspects (the latter concerning anthropology, sociology and education), supported by a broad-ranging documentary review of primary sources. The results lead us to sustain that, within the internal logic of Prisoner's Base, there are the underlying socialising codes of contemporary education, through which its lasting presence guarantees the theory of the "process of civilisation" in the West. This interpretation also contributes to valuing its phenomenological comprehension within the history of physical games and the role that these play in society.

Key words: History of Physical Education; Prisoner's Base; History of Sport; Traditional Games.

\footnotetext{
${ }^{1}$ Correo electrónico: jbrasorius@ub.edu. ORCID ID: https://orcid.org/0000-0002-3582-9826.

${ }^{2}$ Correo electrónico: xtorreba@gmail.com. ORCID ID: http://orcid.org/0000-0002-1922-6785.
} 


\section{INTRODUCCIÓN}

Como trata Parlebas (2001), a través de un análisis de la "lógica interna" de los juegos, encontramos los rasgos que identifican la cultura a la que pertenecen, puesto que «ilustran los valores y el simbolismo subyacentes de esa cultura: relaciones de poder, función de la violencia, imágenes del hombre y la mujer, formas de sociabilidad, contacto con el entorno" (Parlebas 2001: 223). Es a partir de este autor — que aporta el concepto de etnomotricidad; es decir, la etnología de la motricidad-, y con el propósito de analizar las identidades socioculturales de los juegos tradicionales y populares, que el presente artículo se centra en el análisis particular del juego del marro, quizás el juego motor de persecución y estrategia entre bandos más ancestral que se conoce en Occidente. Con el citado juego, como objeto de estudio, se pretende también averiguar por qué ha permanecido durante tantos siglos prácticamente inalterado, siendo hasta los inicios del s. XX una de las principales recreaciones preferidas por jóvenes y maestros.

Vayamos pues, y en primer lugar, a conocer cómo se juega al marro según la descripción que ofrece Parlebas:

En este juego hay dos equipos simétricos que disponen de sendas barreras inviolables (zonas protegidas o casa), situadas en los extremos de un campo rectangular, y que se enfrentan en el espacio que separa ambas barreras mediante un simple toque. El derecho del jugador, su derecho de captura (y su riesgo de ser capturado), está directamente relacionado con el tiempo, con la circunstancia del momento de su entrada en el territorio de enfrentamiento. Cuando un participante sale de su zona protegida, si uno de sus adversarios sale de la misma "antes" que lo haga el primero, tiene "marro" respecto de este (es decir, que el último en salir le puede hacer prisionero/a solamente con tocarlo); y al mismo tiempo, recibirá marro de cualquier adversario que salga de la zona de casa "después" que él. La regla es bastante fácil de expresar, pero su puesta en práctica requiere una notable capacidad cognitiva, ya que cada jugador debe, dentro del espacio de enfrentamiento, tener en cuenta a sus contrincantes (a los que puede capturar pero que también pueden capturarlo a él) y a sus compañeros (a los que puede proteger y que pueden intervenir en su ayuda), de acuerdo con las distancias que los separan y en función sobre todo de los respectivos tiempos de salida (Parlebas 2001: 449).

Los abundantes registros del marro localizados en la bibliografía del siglo XIX y XX y en la literatura especializada es una prueba de la supervivencia — continuidad y estabilidad temporal - del juego, aunque ello no excluye la posibilidad de encontrar variantes locales, como en el caso mismo de sus diferentes denominaciones - marro, moros y cristianos, rescate, rescat, prisioneros... Enumerar las variantes del juego (históricas y territoriales) ocuparían otro trabajo que se escapa de nuestro objetivo, si bien pueden consultarse para ello las obras de Allemagne (1903) y Guillemard, Marchal, Parent, Parlebas y Schmitt (1988).

El alcance histórico del juego del marro es muy extenso y, siguiendo las noticias sobre su origen en Europa, descubriremos su significación antropológica y cultural. El primer aspecto destacable es el conocimiento de la actividad en numerosos países. A modo de ejemplo, el juego era conocido como: barres o Le jour e la nuit —en Francia-, Prisoner's Bars o Prisoner's Base —en Inglaterra-, Giorno e notte, Paladini, Barrierre o barre —en Italia_, Tag und nacht o Das Mattmachen —en Prusia, Alemania-, y como rescat o riscat —en Cataluña. 
Siguiendo a Caillois cuando analiza la vocación social de los juegos, el marro ha sido durante siglos uno de los juegos que, por sus manifestaciones simbólicas y lógicas, ha permitido un encaje conciso en las costumbres de muchas poblaciones. Caillois (1986: 86), cita que son precisamente estas manifestaciones las que "contribuyen en efecto a dar a las diferentes culturas algunos de sus usos y de sus instituciones más fácilmente identificables".

De las raíces psicológicas más profundas surge el juego simbólico de "atrapar" al otro — de poseer al otro-, una manifestación humana primitiva —-depredadora quizás- que se verá modificada por el proceso evolutivo de la ontogénesis y la sociogénesis, en otras formas de juego más complejas.

Entre todos los juegos de persecución, el del marro es uno de los más antiguos y ha mantenido durante siglos la permanencia de una liturgia simbólica que surge del dualismo entre el eros y el thánatos, la supervivencia y la muerte, rituales imperecederos en los juegos de combate de bandos. La raíz simbólica del juego del marro nace en la esencia existencial del propio individuo y, socialmente, se apoya en el grado de complejidad que reúnen las estrategias sociomotrices y los roles que se manifiestan en el resto de individuos de ambos bandos (Parlebas 2001; Brasó y Torrebadella 2014).

Como trata Caillois (1986: 45), en los juegos de agon y en el del marro, la ficción de la seriedad que adquieren los participantes les implica disciplina, esfuerzo y perseverancia que pueden conducir a "una forma pura del mérito personal y sirve para manifestarlo".

La influencia del ejercicio físico y de los juegos corporales en el proceso de configuración de la educación física en España en el siglo XIX y primer tercio del siglo XX vino auspiciada por una substancial bibliografía de los tratados de juegos y recreaciones infantiles (Bantulà 2006; Torrebadella 2011). En estos tratados higiénicopedagógicos y recreativos, el juego del marro fue generalmente considerado como uno de los más populares y preferidos (Brasó y Torrebadella 2015c). Este punto nos permite interpretarlo como un dispositivo pedagógico en el dominio corporal y, posteriormente, trazar una interpretación sociológica en el llamado proceso de civilización.

Especialmente en este juego es donde podremos encontrar, como apunta Bantulà (2006), el escondido aleccionamiento social de los valores de la clase burguesa sobre la juventud. Esta apreciación deberemos conjugarla con otras tesis en donde los juegos son utilizados por los grupos dominantes como dispositivos para perpetuar el poder y marcar las diferencias en la distinción social de las élites del siglo XIX, artífices conducentes del proceso de civilización que experimentaron los juegos y recreaciones corporales al transformarse en lo que llamamos deporte (Elias y Dunning 1992).

\section{METODOLOGÍA}

En cuanto a la metodología, el estudio parte de un enfoque histórico y fenomenológico interdisciplinar — antropología, sociología y pedagogía - y se apoya en una extensa revisión documental, tanto de fuentes primarias como historicistas. Las referencias documentales de la época han servido para trazar primeramente un análisis hermenéutico en la antropología social que trata de esclarecer aquellos elementos que fundamentan el carácter de un proceso educativo y la conexión que se fija entre ellos 
(Mélich 1994). Asimismo, consideramos nuestros estudios anteriores, que abordaron los juegos corporales y el marro en la educación física y sociedad española del siglo XIX y primer tercio del siglo XX (Brasó y Torrebadella 2014, 2015b, 2015c). Nos hemos servido también del método genealógico que utiliza Foucault a partir de Nietzsche (Foucault 1979) y de autores que han abordado el estado de la cuestión desde diferentes perspectivas y ámbitos de las ciencias sociales. Autores como Norbert Elias o Michel Foucault permiten abordar la yuxtaposición compleja y diversificada de las relaciones que participan en el ejercicio del poder y la formación de crear dispositivos de subjetivación (Varela 2003). Son pues estas aproximaciones de análisis y su interdependencia las que alumbran la teoría que construimos —una generalización hipotética- y el discurso ideológico que identifica la lógica interna del modelo teórico que presentamos.

Por otro lado, debemos señalar que la abundante bibliografía aquí utilizada viene a reforzar el análisis de un marco de investigación nuevo, al menos en lo que concierne a este juego. Por esto no podemos desperdiciar todo cuanto se halla escrito sobre el marro, ya que como cita Foucault (1979), contribuye a una erudición necesaria para este tipo de enfoques.

\section{"EL MARRO", ORÍGENES Y NOTICIAS DEL JUEGO}

Entre los fundamentos de la civilización de occidente es ineludible no prescindir del legado clásico griego. Como cita Diem (1966a: 118) "a los griegos les debemos la máxima: no hay educación sin deporte, no hay belleza sin deporte; solo el hombre educado físicamente es verdaderamente educado, solo él es en efecto hermoso". Entre los griegos el juego era también muy popular y practicado como un ejercicio guerrero entre los niños e incluso tenían sus propios campos de juego infantiles.

En Esparta, cuando las envidias de Atenas la obligaron a prepararse al combate, la legislación urbana creó sin número de juegos gimnásticos, para dar así una educación puramente militar a sus jóvenes, y está suficientemente probado que el difícil ejercicio de la barra era el más frecuente de todos (Perillan 1873: 168).

En los estudios antropológicos sobre los orígenes del juego deportivo podemos considerar la antigua Grecia como el punto de partida de cualquier análisis (Andreu 2009; Caro 1978; Paredes 2002; Perillan 1873). Que el deporte contemporáneo tiene sus orígenes ancestrales y retrospectivos en los juegos de la Antigua Grecia es una tesis más que tratada en muchísimas aportaciones historicistas sobre los Juegos Olímpicos.

Los ancestros del juego del marro también se remontan a los tiempos de la Grecia Antigua, que lo concibieron como un juego simplificado o modificado como preparación a la guerra. En el siglo V a. C. en Atenas el juego del marro fue conocido con el

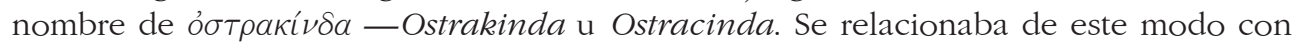
el castigo griego por ostracismo, consistente en expulsar a un habitante de la ciudad. Los niños, mediante una teja o una concha, determinaban el equipo que tendría que ser castigado-perseguido, y por lo tanto, tenía que huir. Según Becq (1869) en el juego de la teja, tejuela o concha - y sus dos caras: blanca y oscura- se encuentra oculto 
el axioma que sustenta la creación del Estado democrático de los atenienses; es decir, el principio legislativo que ponderaba el equilibrio entre las fuerzas antagónicas y simbólicas propias de la atemporalidad humana. Las dos caras de la concha, la división del campo de juego entre dos espacios, los dos bandos opuestos, las acciones antagónicas del juego — perseguidor y presa, jugador libre o preso- y el objetivo hasta alcanzar la eliminación del bando adversario, son la representación simbólica del dualismo entre la vida y la muerte, el día y la noche, la luz y la oscuridad, el este y el oeste, el calor y el frío, la paz o la guerra, el hogar y el campo de batalla, la infancia y la madurez, la victoria y la derrota, la fortaleza y la debilidad, el amor y el odio, la fertilidad y la destrucción, la mujer y el hombre, o el ciudadano libre y el ciudadano desterrado. Como menciona Pollux -1, libro IX, 111- estos conceptos antagónicos representan una dualidad de dos principios que no pueden existir simultáneamente (Allemagne 1903). El lanzamiento de la concha, tiene como objeto conocer de antemano el oráculo, y cuestionar el destino o el designio de los dioses, pero para que sea posible debe regir el orden, la perseverancia y el esfuerzo.

En el transcurso del tiempo podemos comprobar cómo a través del estudio de diferentes fuentes documentales, iconográficas y literarias, el antiguo juego ha subsistido prácticamente hasta no hace mucho (Allemagne 1903; Becq 1869; Caro 1884; Grasberger 1864; Mehl 1990). Hasta hace poco de este juego se decía que era "muy parecido, casi en todo semejante, al que hoy se juega" (Costumbres antiguas 1846: 6; Jeux des enfants 1845: 319). En Atenas, el célebre Platón argumentó la necesidad de adaptar los ejercicios corporales al desarrollo de los niños y de las niñas (Castellanos 1850; Diem 1966a).

Rastrear la arqueología normativa de este juego es muy difícil ya que las adaptaciones y su nombre han variado a través del tiempo y los lugares. Asimismo, tampoco en el ámbito europeo es fácil indagar sobre el juego.

Los romanos jugaron al ostrakinda, al que llamaron juego de "la concha" (Allemagne 1903). Los orígenes del marro son remotos y puede que su presencia en las diferentes naciones sea debida a la ocupación romana (Becq 1869; Cambi y Staccioli 2007; Caro 1884; Lillo 2004).

Según Mehl (1990), en Francia las primeras noticias del juego se localizan en el siglo IX. Hacia principios del siglo XIV ya era conocido con el nombre de barres, dicho así en referencia a las dos líneas o barres trazadas en el terreno de juego que delimitaban las zonas de los dos bandos (Allemagne 1903).

Podemos establecer la hipótesis de que el juego emulaba las disputas guerreras medievales y las escaramuzas en "el rescate de prisioneros y cautivos" (Calderón y Díaz 2011). También se relacionaría con los juegos de niños y torneos como los que trata Dunning (2003: 65-66), al referirse que los testimonios más antiguos que existen sobre los torneos son del siglo XII y se caracterizan por su violencia: "Los torneos típicos — cuentan- eran un tumulto compuesto por partidas de caballeros que luchaban al mismo tiempo, que capturaban a otros, que luchaban no solo por la gloria sino también por los rescates".

En Francia, uno de estos juegos era la mêlée; es decir, torneos entre bandos, en donde el objetivo consistía en vencer y hacer prisioneros del equipo contrario para exigir un premio o rescate (Corriente y Montero 2011; Flori 2001). Esta es la misma visión que hacía Mutel (1846: 152) al considerar el juego del marro como un juego 
de guerra "que era antiguamente un combate de hombres en un espacio cerrado de barreras".

El juego alcanzó su popularidad plena en los siglos XV y XVI, período que se instala como práctica distintiva de la recreación física entre los jóvenes en el ámbito rural y escolar. En estos siglos se produjo la transformación gradual de los señores guerreros —caballeros medievales- en nobles cultivados — cortesanos-, que en consecuencia fue acompañada de una natural reducción de la barbarie de los torneos deportivos. Este nuevo paradigma sirvió para desplegar todo un proceso gradual de civilización - humanista, burgués y de entrada en la época moderna- hacia formas menos violentas y sangrientas de recreación (Elias 2010).

A partir de entonces los juegos experimentaron un proceso de pedagogización —civilización-, si bien el sentido recreativo del juego no cambia y permanecía inalterado - también por lo que respecta a la lógica interna de duelo entre bandos. Al incorporarse en el seno del marco escolar católico — humanista de los jesuitasde los siglos XVI y XVII de la sociedad burguesa que cita Varela (1986), juegos como el del marro experimentaron normas para reducir la violencia (Brasó y Torrebadella 2015c), es decir, de protección a la infancia heredera.

El humanismo del periodo renacentista reencontró la visión platónica del hombre y puso en la escena social las celebraciones lúdicas, que simbólicamente expresaban un rasgo que reivindicaba el antropocentrismo y los placeres terrenales, frente al oscurantismo católico y ascético. Asimismo, desde la Iglesia católica se presenta la eutrapelia de la ética de Aristóteles como una virtud decorosa que acepta la recreación de los juegos lícitos que sirven para ejercitar las fuerzas y ganar en salud. En este orden son recurrentes en literatura Re ludisque de los siglos XVI y XVII destacar los juegos de pelota, de saltos, lanzar la barra, el tejo, la ballesta, la argolla, los bolos o las carreras (Alcocer 1559; Covarrubias 1543; Mariana 1845; Remón 1623).

La visión humanística permitió el ascenso de los valores culturales del juego y forjó las bases que condujeron a las élites cortesanas a fijar una liturgia de diferenciación social. Esta posición en las costumbres y recreaciones cortesanas de la nobleza y de la burguesía emergente lleva implícito el llamado proceso de civilización que Elias y Dunning (1992) sostienen al tratar la institucionalización del deporte. Sin duda alguna, el juego de pelota - o giuoco della palla en Italia o jeu de paume, en Francia- representan el testimonio más fehaciente de este cambio (Bantulà y Vilanou 2009). Además, el humanismo (re)establece los juegos corporales en una visión higiénicopedagógica que se despunta en Italia por las aportaciones de Feltre, Vegio, Palmiere o Castiglione; en Inglaterra por Mulcaster, Eliot y Ascham, y que en España es representada por Nebrija, Vives, Méndez o Alcocer (Álvarez 1995, 1999).

Las habituales referencias historicistas para ilustrar la emergencia cultural del juego en la sociedad renacentista tienen como protagonistas al doctor François Rabelais (1490-1553) y al pintor flamenco Peter Brueghel (1525-1569). Pero, ¿qué tienen en común estos dos autores y sus obras? La hegemonía popular del juego se puede palpar en Gargantúa (1534), la magnífica obra literaria de Rabelais (2007), que identifica los numerosos juegos de la tradición popular. Rabelais pretende postrar el juego como una actividad hedonista que denuncia las censuras ejercidas por el dogmatismo de la Contrarreforma — de aquí la prohibición de la obra de Rabelais por el Concilio de Trento- que estaba ejerciendo sobre las clases menesterosas. Aunque es preciso se- 
ñalar, como aclara Elschenbroich (1979), que raramente Rabelais trata el juego como un medio pedagógico o terapéutico.

Asimismo, la alegoría humanista del artista Brueghel en el óleo "Juegos de niños", pintado en 1560, llama poderosamente la atención por lo que respecta al patrimonio etnográfico y cultural de occidente y, probablemente, reivindica el derecho de la diversión pública de las clases menesterosas, revelándose contra el catolicismo que imponía el dominio español de Felipe II en los Países Bajos y que prohibía las celebraciones populares (Elschenbroich 1979).

En este período muchos de los juegos tradicionales alcanzaron un alto nivel de sociabilización corporativa, puesto que llegaron a reglamentarse en competiciones disputadas entre villas, parroquias o gremios profesionales. Así lo confirma en Francia Didron (1851), al situar en 1432 una competición del juego de las barres entre los jóvenes de Béthune y de Lents disputándose como premio una copa de bronce. Otros encuentros de esta índole son abordados por Mehl (1990), al considerar que en el país galo se marcó una incipiente institucionalización deportiva del juego, debido a la omnipresente confrontación de las barres, que siempre fue muy apreciada por las autoridades, por ser una actividad recreativa tradicional, que incluso llegó a ser requerida en la corte parisina de Carlos VIII (1470-1498).

Las contiendas solían realizarse los domingos, en lugares en los que concurría el público que se identificaba a favor de los equipos participantes. Había pues, un espectáculo organizado previamente, en el que se disputaban premios otorgados por los príncipes o nobles. Para participar en el juego se requerían los mozos más fuertes y ágiles de cada comunidad, puesto que las disputas para atrapar o esquivar tenían un carácter violento. Por la habilidad en el juego estos mozos solían adquirir un reconocido prestigio. Es por esta razón de combatir y ganar a los mozos más fuertes por lo que el joven Gargantúa jugaba también a las barres (Rabelais 2007).

En el siglo XVI el juego alcanzó una popularidad entre los jóvenes de posición distinguida y fue práctica habitual en algunas universidades. En 1520 los alumnos del Colegio de Grenoble pedían a las autoridades el poder jugar los martes y los jueves y días festivos al juego de barres (Pilot 1841). Esta misma recreación y ejercitación era apreciada por Montaigne; en los Ensayos atendía la necesidad del adiestramiento físico como una parte más de la educación del noble. Así, cuando consideró los ejercicios corporales de los escolares citaba qui courrent aux barres et pour exercer leur course (Montaigne 1887: 173). Asimismo, Ulmann (1977) detecta en los colegios de la ordenación jesuita la presencia del juego de barres como uno de los ejercicios viriles dirigidos a formar el carácter de los nobles.

En Inglaterra se tiene noticia del juego Prisoner's Base en el siglo XIV. Cuenta Strutt (1801) que en el reinado de Eduardo II (1307-1327) el juego del Ostrakinda era conocido como Cross amb pile — cara o cruz-, del que decía ser un pasatiempo vulgar y muy conocido entre las clases más bajas, aunque llegó a ser practicado en la Corte y pronto adquirió un rango más distinguido. En otro apunte menciona que en tiempos de Eduardo III (1312-1377), los niños jugaban en los alrededores del palacio de Westminster, impidiendo el paso de los transeúntes, hecho que provocó su prohibición. El juego perduró durante todo el Renacimiento y continuó siendo uno de los pasatiempos más apreciados por los jóvenes (Griffin 2005; Leibs 2004).

En 1770 cuenta Strutt (1801) que vio jugar un espectacular partido de Prisoner's 
Base en Londres, en los campos de atrás de Montague House -Museo Británico- entre doce caballeros de Cheshire contra doce de Derbyshire, los cuales se disputaron una importante suma de dinero.

Por otro lado, en el siglo XVII el asentamiento popular del juego de barres fue ocupando el lugar correspondiente en los diccionarios; unos valiosos materiales que nos indican acerca de las acepciones y las diferentes variaciones lexicográficas de muchos juegos. Así por ejemplo, Oudin (1607: 35), en Thresor deux langues espagnolle et françoise, anota que le jeu de barres tiene su acepción en español al llamado "lugar de tirar barra y luchar". Fleury (1656) apunta que el juego tiene una procedencia griega en los ejercicios olímpicos de las carreras, y que en Francia se adoptó originariamente con el nombre de barres. Por eso en España, en ocasiones, se ha traducido Les barres al castellano erróneamente con el nombre de "juego de las barras" y, además, no tenía que ver nada con el juego del lanzamiento de la barra (Agasse 1797; Van Torre 1746).

El padre jesuita Antonio Van Torre (1615-1679) en Dialogi familiares (primera edición de 1657), una obra humanística muy conocida del siglo XVII y XVIII, escrita para el aprendizaje del latín en forma de diálogo, presentó Le jeu des barres como una de las recreaciones preferidas por los escolares de la época (Bantulà 2005; Van Torre 1746). Igualmente, se citaba que esta recreación fue muy popular en tiempos de Luis XVI (17541793) y practicada por las guarniciones de la casa real (Fernández de los Ríos 1852). En España, el padre Benedictino Luis Olod (1766) incorporaba el juego del marro como uno de los ejercicios más saludables para la recreación y la mejora de las fuerzas.

Como trata Hesse (1967), Rodrigo Caro (1884) en Días geniales o lúdicros - manuscrito original de 1626- trazó la primera genealogía de los juegos que se practicaban en España. Caro (1573-1647), culto sacerdote y apasionado por la arqueología, demostró en este tratado (que nunca llegó a publicar en vida) como muchos de los juegos de su época tenían sus raíces antropológicas en la cultura griega y romana. Esta tesis fue presentada anteriormente por Jerónimo Román (1595: 419) en las Repúblicas del mundo, indicando en el Libro de la "República Gentilica" que "hay otros juegos de muchachos que los usamos nosotros y quedaron por sucesión desde los antiguos". Para Etienvre, que presentó la primera edición crítica de Días geniales o lúdicros, Caro (1978) aportó el documento más valioso que existe en España sobre los juegos en los siglos XVI y XVII, y por añadidura, en pleno apogeo del barroco español, contribuyó con una valiosa obra etnográfica y primigenio estudio del folklore (Graupera-Sanz 2010). Sin embargo, la intencionalidad de Caro era clara, puesto que deseaba legitimar la herencia clásica de los juegos corporales con el propósito de recuperar sus peritas enseñanzas entre los muchachos españoles:

De manera, que sacamos por conclusión verdadera que conviene mucho ejercitar los muchachos en las fuerzas corporales, pues dos Repúblicas tan sabias, tan antiguas y tan poderosas lo tuvieron, no sólo por entretenimiento y alegría de los pueblos, sino también por doctrina necesaria para que los mozos se criasen fuertes y robustos para la guerra y para vivir mucho (Caro 1884: 94).

Asimismo, los últimos estudios realizados sobre esta obra de Lavega y Navarro (2015: 500) apuntan que los juegos que se presentan acentúan y confirman el llamado proceso de deportivización de los juegos que enuncia Parlebas (2001); es decir, un siste- 
ma de participación organizada con muchas de las características estructurales del deporte moderno.

Precisamente, uno de estos juegos de herencia clásica, sujeto al proceso de deportivización era el Ostracinda, que según citaba Caro, citando a Platón, consistía en:

[...] divididos los muchachos en dos bandas, hacían una raya en medio: á una de las bandas llamaban dentro deja la texa, y á otra fuera de la texa; esta texa tomaba uno arrojábala á la raya. El que vencía partía corriendo, y todos los de su banda con él, y daba tras de los de la banda vencida, que iban huyendo: el que de estos era cogido del que iba tras él le llamaban Asno, el cual tomaba la texa y decía noche ó día, porque por la parte de adentro estaba empegada y correspondía á la noche. Este juego se llamaba Vuelta la teja (Caro 1884: 233).

Este juego tenía en tiempos de Caro muchas similitudes con el citado "Daca la china", y admitía que como solía suceder con algunos juegos, iban modificándose con el tiempo algunas formas o ceremonias, pero destacando que la esencia continuaba siendo la misma doctrina general:

Ese juego tiene algunas cosas parecidas al juego que llaman Daca la china, que es de esta manera: hacen los muchachos una raya, y dividiéndose en dos bandas, uno toma una tejuela y mójala en saliva, arrojándola en alto, diciendo: “¿ino ó pan?” Responde el otro: "Vino, que Dios dará pan, ó pan, que Dios dará vino". El que acierta queda hecho rey ó capitán de aquella banda; y dispuestos los muchachos, sentados en el suelo, cada uno pide que le den la tejuela. El capitán de todos la da á quien le parece, tan disimuladamente que no lo puede echar de ver el otro capitán su contrario, el cual anda tentando las orejas á los muchachos, para ver si por alguna señal puede echar de ver quién tiene la tejuela ó la china. Si acierta con ella, se la lleva á su banda; si no, van saltando los de esta banda que tiene la china, hasta que lleguen á aquella raya. En tocando en ella huyen los vencidos. Los vencedores van tras de ellos persiguiéndolos; si cogen alguno, el que lo coge le llama Asno, y se le pone á cuestas y lo ha de traer hasta aquella raya (Caro 1884: 234).

En un anterior trabajo nuestro (Braso y Torrebadella 2015c) ya mencionamos las referencias que de este juego incorpora Pelegrín (1998), subrayando la voz y la acepción del juego del marro en el Diccionario de Autoridades (1734): "Marro. Se llama también el regate o hurto del cuerpo para no ser cogido y burlar al que persigue". Por lo que el juego era entendido como sigue:

Marro. Significa también juego parecido al que llaman Moros y Christianos, en que puestos dos bandos de una parte y otra encontrados, dexando suficiente campo en medio, salen de uno y otro a coger o tocar el contrario: y el arte consiste en huir el cuerpo el uno al otro, para que no le cojan o toquen, retirándose a su bando, porque si le tocan queda prisionero, por lo que le dieron este nombre (Autoridades 1734: 504).

La localización del marro en el Diccionario de Autoridades indica la aceptación popular del juego, bastantes años antes de la fecha. Así, comprobamos que durante los siglos XVI y XVII el término "marro", aunque también pudiera referirse a otros juegos relacionados con las "tejas" o "marros" — trozos de teja-, tenía también su validez. Asimismo, Pelegrín (1998) apunta que el marro puede tener un parecido a otros juegos como el cautivos, como el que Alonso Ledesma (1611) incorporó en Juegos de Noche Buena Moralizados. Ledesma aporta un alegórico romance de este juego ha- 
ciendo del mismo un simbólico paralelismo de la lucha de la virtud cristiana contra la tentación del pecado.

Podríamos llegar a pensar que el juego del marro fue incorporado en España por influencia francesa hacia el siglo XVI, pero también pudiera ser que ya existiera desde mucho antes. En este sentido, es notorio también destacar la hipótesis de Westerveld, en la que propone que el origen de la palabra marro es catalana - y luego adquirida por diferentes territorios-, significando juego de fichas. Esta suposición viene reforzada por el hecho de que con este mote se identificaban otros juegos (Amades 1984; Brasó y Torrebadella 2015a, 2015c; Brasó y Collell 2016), como el tres en raya, la rayuela, el juego de la barra, y otras prácticas donde intervenía una ficha o pieza - o más de una. Asimismo, detalla que al juego de las damas se le llamaba marro de punta - se encuentran obras con este nombre a partir del s. XVI-, y que deriva del ajedrez. El nombre de marro aparecería alrededor del s. XIII. Pero además, otro significado de la palabra marro equivaldría también a los conceptos de la agudeza y el ingenio (Westerveld 2014). Aceptando esta hipótesis, habría una alta relación por lo que respecta a las altas habilidades cognitivas — tácticas y estratégicas- que requieren el ajedrez, las damas, y las que se solicitan para el juego motriz del marro.

La falta pericial de pruebas documentales hace que tengamos dudas sobre la existencia de este juego, en el ámbito motriz, anteriores al siglo XVI. Las primeras referencias testimoniales aparecen a principios del s. XVII. En el juego de Los cautivos de Ledesma (1611), o la obra de Suárez (1630) se encuentran estos inicios —posteriores al primer tratado de damas, apellidado también marro de punta-, hecho que refuerza la denominación del nombre partiendo de los juegos de fichas, de tablero y del alto nivel cognitivo requerido. No obstante, conocemos que a partir de estas primeras apariciones del s. XVII, el juego experimentó variantes de nombre o modificaciones normativas a lo largo de la historia (Brasó y Torrebadella 2015c). Asimismo, como indica Solana (1943: 110): "Del marro se derivan entre otros juegos, el del contrabandista, justicias y ladrones, moros y cristianos, conquista de la bandera, etc.".

\section{"EL MARRO" COMO DISPOSITIVO SOCIOPEDAGÓGICO DEL DOMINIO CORPORAL}

A partir del siglo XVII se produce un proceso de escolarización por parte de las congregaciones católicas en donde el ejercicio corporal es presentado como una sana recreación compensatoria al trabajo intelectual, pero también el juego tiene la función de ser un medio profiláctico ante las amenazas perturbadoras de la adolescencia. Bajo estos preceptos el juego se presenta, a partir de la eutropelia aristotélica y la moral cristiana, con la intención de fijar el patrón de conducta que emana de las costumbres burguesas emergentes (Bantulà 2005).

Siguiendo la máxima del fundador San Ignacio de Loyola de la Compañía de Jesús, en los colegios jesuitas el endurecimiento corporal constituyó un elemento concomitante del proceso educativo (Diem 1966b). En la figura de Juan de Mariana (15351624) es donde podemos encontrar trazada la línea doctrinal de la instrucción corporal jesuítica. Tanto es así, que Miguel Piernavieja (1963: 367) ya aludió la obra del padre De Mariana (1845), Del rey y de la institución real - de 1599- como uno de los mejores tratados pedagógicos para el asentamiento de la educación física escolar, aña- 
diendo que se adelantaba «en casi dos siglos a los primeros creadores del método racional, los alemanes Basedow, Salzmann y, sobre todo, Guts Muths». Otros jesuitas, como Juan Eusebio Nieremberg (1629) o Lorenzo Hervás (1798) se mostraron favorables a estimular concursos públicos, para fomentar los ejercicios corporales entre el pueblo. Entre estos juegos, el juego del marro que trataba Antonio Van Torre (1746) era uno de los preferidos en la Compañía.

Los colegios de la Compañía marcan para Foucault (2012) el curso de la escolarización jerarquizada y disciplinada. Los jesuitas son los encargados de formar a los hijos de la clase dirigente bajo la disciplina militar y con un sistema de premios y castigos, que tiende a garantizar la obediencia. La congregación jesuita perpetra un sistema que se fija en el idealismo del caballero cristiano del medievo bajo un punto de vista clásico. La Compañía funde la disciplina corporal del guerrero con la disciplina moral del cristiano (Varela 1983). Este ideal, que podemos encontrar simbolizado en el juego de Cautivos (Ledesma 1611), presenta la abnegación por la lucha que ya pedía san Pablo, que al fin y al cabo no era otra que la expresión aristotélica relacionada con que "no se debe educar al cuerpo sino para servir al alma" (Pastor 1997: 38) y con el vínculo de obtener un cuerpo sano y robusto para servir mejor a Dios. Así postulaba el jesuita Francisco Aguado (1641) que, al tratar las exhortaciones doctrinales del buen cristiano, encontró que tanto los ejercicios corporales como los ejercicios espirituales siguen la misma norma para alcanzar sus fines: la conservación del cuerpo y la salvación del espíritu.

El padre de la Compañía de Jesús Gerónimo Rosales (1725) mencionaba que los juegos y entretenimientos honestos de los niños eran aquellos destinados al ejercicio corporal, al fortalecimiento del cuerpo y a la mejora de la salud, de ahí que detallaba el marro, la barra, los bolos y la pelota. Como comprobamos, el primer juego que citaba era el del marro, sin duda alguna el único que se jugaba con bandos.

Por otro lado, el juego del marro representa para el maestro una situación a examen de los alumnos, que los observa atentamente — quizás tras una ventana-, que apunta, memoriza y clasifica el carácter de los jóvenes. Este juego entra de lleno en los mecanismos de las disciplinas, que para Foucault son mecanismos de dominación, que fabrican cuerpos sometidos, obedientes y dóciles. En las escuelas dirigidas por los jesuitas, el marro ya se ha subscrito al proceso de civilización que huye de la violencia y que se presta al servicio de "las tecnologías pedagógicas que funcionan según mecanismos de clasificación" (Bárcena y Mélich 2000: 71). El marro también entra a formar parte del examen como dispositivo de control social y de ejercicio del poder que distingue, califica, valora y jerarquiza a los muchachos.

Es por ello que el juego del marro es admitido en los colegios de jesuitas, lugar en donde se alcanza un elevado grado de militarización, como sucedió con el Real Seminario de Nobles de Madrid cuando fue dirigido por Lorenzo Hervás (Andújar 2004; Torrebadella 2013). Es entonces cuando los colegios de jesuitas se convierten en internados, una especie de convento-cuartel. Esta organización, considera Foucault (2012: 159), que permite "el control minucioso de las operaciones del cuerpo, que garantizan la sujeción constante de las fuerzas y les imponen una relación de docilidad-utilidad es a lo que se puede llamar 'disciplinas'”. Es decir, Foucault advierte técnicas disciplinarias —de control escolar- de cómo se actúa sobre el adiestramiento (corporal y mental) en los colegios de jesuitas en el siglo XVII. En las clases, la organización de los alumnos era en grupos de diez alumnos: 
Cada uno de estos grupos, con su decurión, estaba colocado en un campo, el romano o el cartaginés; a cada decuria le correspondía una decuria contraria. La forma general era la de la guerra y la rivalidad; el trabajo, el aprendizaje, la clasificación se efectuaban bajo la forma de torneo, por medio de enfrentamiento de los dos ejércitos; la prestación de cada alumno estaba inscrita en ese duelo general; aseguraba por su parte la victoria o las derrotas de un campo y a los alumnos se les asignaba un lugar que correspondía a la función de cada uno y a su valor como combatiente en el grupo unitario de su decuria (Foucault 2012: 169).

Efectivamente, parece que las clases estaban organizadas en bandos, cada uno con su capitán, cada sujeto con sus funciones en la organización estratégica del grupo, una actuación académica que simulaba el orden militar romano y acaso el mismo juego del marro.

Sin embargo, fue en las escuelas prusianas protestantes donde la educación física y los juegos corporales alcanzaron un alto grado de consideración. El juego del marro, junto a otros juegos corporales, es recuperado por Salzmann y Guts Muths. Estos personajes, influenciados por las doctrinas de Locke, Tissot, Rousseau o Frank, aplican en los juegos una política con doble intencionalidad. De un lado, desean preservar la higiene y procurar el endurecimiento corporal de los alumnos y, al mismo tiempo, tienen como finalidad la de modelar el carácter y la moral de estos. El juego se presenta como el medio pedagógico para conseguir la condición disciplinada que exige Kant a la educación, pero también tiene el carácter de la fase de asimilación que manifiesta el constructivismo social de Piaget y Vygosky (Omeñaca y Ruiz 2003). En definitiva, con el juego se pretende obtener alumnos sanos para prevenir la degeneración, y evitar la corrupción de los vicios corporales y morales, pero también se pretende formar una población fuerte y dócil para generar el futuro combatiente, que tanto interesó a los griegos y luego a los alemanes.

El juego del marro se presentó en la educación física a partir de la obra que Johann Christoph Friedrich Guts Muths (1759-1839) publicó en 1796 en Schnpfenthal, Juegos para ejercicio y recreo del cuerpo y del espíritu dedicado a la juventud-Spiele zur uebung und erbolung des körpers und geistes, fur die jugend. De este tratado, según Diem (1966b) se realizaron nueve ediciones. Guts Muths introdujo el primer compendio recopilatorio de juegos, especialmente de movimientos gimnásticos, con una finalidad higiénico-pedagógica. El tratado es una erudita revisión antropológica del juego, que tiene como origen la incorporación de muchos de los juegos de la Antigua Grecia. Como cita el autor, a través de los juegos se puede definir el espíritu y el carácter moral y político de pueblo, puesto que siempre han sido utilizados como recursos educativos de las naciones (Guts Muths 1796). Los juegos que incorpora Guts Muths y otros ejercicios gimnásticos fueron ensayados en el Philantropinum de Salzmann en Schnpfenthal (1784), un internado que seguía el modelo del Philantropinum de Basedow en Dessau, y en el que se dispuso de toda una escrupulosa organización controlada al detalle (Elschenbroich 1979). El consenso historicista ha situado al Philantropinum de Salzmann y la intervención técnico-pedagógica de Guts Muths como el punto de partida contemporáneo de la educación física escolar en Europa.

Basedow prohibió severamente los juegos espontáneos y tradicionales de la infancia que estimulaban la imaginación y la creatividad. Siguiendo este criterio, Guts Muths inició una renovación, transformación y creación de muchos juegos para la infancia y la juventud. En estos juegos o ejercicios corporales se organizaban jerarquías de man- 
do entre los participantes, donde se hacía imprescindible la obediencia rápida a las órdenes de los superiores. Para los filántropos estos juegos fueron visionados como un modelo «incluso como espejo, del orden, la sobriedad y la constructividad, bases a su vez, del éxito de la clase burguesa de la que procedían tanto alumnos como profesores" (Mandell 1986: 168-169).

En los Juegos para ejercicio y recreo del cuerpo y del espiritu se presentan los juegos Tag und nacht — día y noche-, del que decía ser el llamado antiguo juego griego ostrakinda, Foppen und fangen —esquivar y atrapar- y Das mattmachen -fatigarse-, y citaba que en Francia era conocido como Les barres y en Inglaterra como Prisoner-Base. Guts Muths seleccionó aquellos juegos que consideró física y moralmente más provechosos para la juventud de los que decía que: "Así logra el discípulo, mediante un genuino y sagaz juego de muchachos, no solo el importante vigor y fortalecimiento del cuerpo, sino también el del espíritu, muchas veces más importante aún" (Elschenbroich 1979: 226).

Guts Muths deseaba lograr un grado de perfección corporal en donde la salud fuese a la par con la fuerza, la actividad con el valor y la resistencia, y la presencia de espíritu con un verdadero carácter viril (Salzmann 1800). Para argumentar este modelo parafraseaba a Rousseau en El Emilio (vol. 2): All the sensual passions take up their abode in effeminate bodies and are the more irritable in proportion as they are less capable of being gratified. A feeble body enfeebles the mind (Salzmann 1800: 83) . $^{3}$

Como precisa Elschenbroich (1979: 226), el programa oculto que los filantrópicos subrayaron para la educación física llevaba implícito el desarrollo de las cualidades "Como el espíritu de empresa, la capacidad de resistencia, la prontitud en las reacciones, la capacidad de imponerse" y atribuye a estas cualidades el carácter que posteriormente adoptó la educación física escolar, centrada y dirigida a sembrar el espíritu de competición, el rendimiento individual y la disciplina castrense. No cabe duda de que la influencia de la obra de Guts Muths inició en Europa el proceso contemporáneo de la pedagogización de los juegos corporales en la educación física escolar. Como apunta Pelegrín (2000), la influencia del alemán se hizo sentir en muchos de los tratados pedagógicos y gimnásticos decimonónicos. Gymnastik für die Jugend fue traducido al inglés en 1800, al francés en 1803 y al castellano en 1807. A partir de la circulación de Gymnastik für die Jugend (1793), por toda Europa se hizo patente la influencia pedagógica de los juegos corporales de Guts Muths. En España esta influencia provino de La gimnástica o escuela de la juventud, una traducción española de la edición francesa de Amar y Jauffret (1807), publicado en atención al Real Seminario de Nobles que en Madrid disponía la institución jesuita (Brasó y Torrebadella 2015c).

Es al llegar el siglo XIX cuando comprobamos como para los adultos la finalidad del juego es otra, y se contempla como un dispositivo antiafeminación y antionanista (Torrebadella y Vicente 2016). Además, ya no se presenta tanto como un juego de preparación a la guerra, ahora lo que preocupa es la salud y el vigor corporal, la esencia del ser animal que cita Spencer (1879), así como también atajar la degeneración de la especie o la "raza" (Vigarello 2005). Todo esto hace que las nuevas prácticas

\footnotetext{
3 Trad.: "Todas las pasiones sensuales tienen su morada en los cuerpos afeminados y son más irritables en la medida en que son menos susceptibles de ser gratificados. Un débil cuerpo debilita la mente".
} 
físicas (gimnástica, juegos corporales y deportes) entren de lleno en la "política corporal modernista" que cita Griffin (2010: 202).

Así pues, a partir del siglo XIX los juegos recreativos de los jóvenes y, en especial, los juegos corporales, se enrolan en un proceso de pedagogización e institucionalización escolar. Estas actividades siguen configurando el proceso de sociabilización o civilización de los antiguos juegos corporales, que según Elias y Dunning (1992) son reglados convirtiéndose, algunos de ellos, en las prácticas deportivas contemporáneas. Una de estas experiencias significativas es recogida en la Escola del Mar de Pere Vergés en Barcelona (Brasó y Torrebadella 2014).

En Francia, el modelamiento de las recreaciones infantiles y de los juegos corporales adquiere un tratamiento en el proceso de sociabilización burguesa de la época preindustrial. En este contexto se teje un adoctrinamiento pedagógico que toma como origen los proyectos educativos prusianos de Basedow o Salzmann de finales del siglo XVIII, en los que la educación física adquiere especial consideración. Se funden las tesis pedagógicas de Comenius, Locke, Rousseau o Kant, pero surgen condescendencias higiénicas y moralizadoras como L'onanisme (1760) de Tissot, que son utilizadas para marcar la diferenciación social de la clase dirigente (Foucault 2001; Vázquez y Seoane 2004). Así, aparecen obras que cooperan a la institucionalización del nuevo modelo de enseñanza. Una de ellas es De l'éducation physique de l'home, en donde Friedlander (1815: 231) se centra ampliamente en los nuevos planteamientos y presenta el poder que pueden ejercer los ejercicios gimnásticos como el juego de barres, del que tout le monde au reste connaît en France le jeu de barres usité dans presque tous les pays du monde.

Otro tratado como Les écoliers en vacances es presentado como la regulación higiénica y moral de los juegos corporales infantiles y adolescentes. En esta obra, el juego de barres ocupa su correspondiente significación como excelente medio de ejercitación corporal preparatorio para la guerra (Brunot-Labbe 1812). Esta percepción era la que también tenía el mismo Napoleón, que gozaba de predilección por el juego de barres, porque mantenía el espíritu joven y además representaba la emulación de la guerra (Defauconpret 1818).

Asimismo, las intervenciones pedagógicas de Salzmann, Guts Muths, Pestalozzi, Clias o Amorós (Diem 1966b), sirven como modelo para incorporar los ejercicios gimnásticos en la escuela y esbozar proyectos educativos. Obras como la Higiène des colléges et des maisons d'éducatión des deux sexes (Pavet 1827) o Traité d’hygiène appliquée à l'éducation de la jeunesse (Simon 1827), tienen el cometido de estructurar una organización higiénico-pedagógica de los colegios internados, donde los ejercicios gimnásticos y los juegos corporales asumen técnicas al servicio de la formación física y moral de los escolares. Los juegos corporales son presentados como excelentes medios para organizar la educación física escolar y, además, cumplen una función preventiva y reparadora ante la corrupción higiénica y moral que acostumbraba a presentarse en los colegios internados (Pavet 1827; Simón 1827). El juego de barres es uno de los preferidos para fomentar la recreación, la formación física y el carácter de estos internados. Pavet (1827: 116) cita de él, que est encore un jeu classique parmi les écoliers, y Simon (1827) lo considera el mejor juego que se puede recomendar a los escolares. Médicos e higienistas decimonónicos también pusieron de relieve las excelencias del marro (Mutel 1846; Pusalgas 1831). 
Durante el siglo XIX el juego fue muy popular en los colegios e internados franceses y recopilado en célebres tratados (Beleze 1856; Celmart 1836; Chabreul 1860). También en los países anglosajones el juego Prisoner's Base fue incorporado en los tratados de juegos y pasatiempos más populares de la primera mitad del siglo XIX (Carver 1834; Clarke 1829; Elliott 1868; Richardson 1848; Uncle 1851; Walker 1837; Warne 1869; Williams y Reuben 1848), algunos de ellos fueron presentados como recursos para atender la educación física de ambos sexos, como el célebre tratado Games and Sports de Walker (1837) o también especialmente considerado para la educación de las niñas (Valentine 1867).

Como ya hemos indicado (Brasó y Torrebadella 2015c), también en España el juego fue incorporado en la mayoría de los tratados de juegos del siglo XIX y en otras obras importantes de la educación física de finales del siglo XIX. La mayoría incidían en la similitud del juego con la guerra, si bien como indicaba Solana (1943: 110), el marro ofrece también "matices variadísimos, lances ingeniosos, carreras rápidas y quebradas que entrañan gran valor educativo".

El que este juego fuese visionado como un excelente recurso de preparación para el combate (la guerra) hizo idónea su aceptación en el movimiento scout, que a la sazón ha sido una de las instituciones que lo ha preservado. Así por ejemplo, cabe destacar la recomendación del juego en las obras Juegos educativos al aire libre y en casa (Jentzer 1921), Manual de gimnasia para uso de los Exploradores Españoles (García 1926), y Manual d'excursionisme (Batista 1927). No en balde el movimiento Scout, como cita Martínez (1993), fue refrendado por Adolfo Ferrière como un ideal sostén de la Escuela Nueva al margen de la oficialidad escolar.

Así pues, en España, como sucedió en otros países de Europa, las adscripciones higiénicas y pedagógicas institucionalizaron el juego del marro en los patios de los colegios privados y también en la educación física escolar. La Institución Libre de Enseñanza, las Escuelas del Ave María del padre Andrés Manjón o el movimiento catalán de las Escuelas Nuevas reafirmaron el juego y sus ventajas educativas, y el del marro era uno de ellos. Por esto, este popular juego continuó apareciendo durante el primer tercio del siglo XX en los manuales de educación física (Brasó y Torrebadella 2014, 2015c).

No obstante, el juego del marro sucumbe ante el proceso de institucionalización deportiva y, aunque intenta ser rescatado como expresión etnográfica (Brasó y Torrebadella 2015b), finalmente queda relegado a una presencia pedagógica (Brasó y Torrebadella 2014).

\section{A MODO DE CONCLUSIÓN}

El juego del marro fue ingeniosamente utilizado como técnica pedagógica para disciplinar el control sobre el cuerpo y la voluntad humana. Sirvió a la llamada "microcirugía del poder" (Foucault 2012), potestativa de las clases dominantes de la época. En el caso del marro, este control se coloniza a través del jefe o capitán del juego, que ejerce como líder, pero que también es vigilado por sus jefes superiores - los maestros-, que están, a su vez, al servicio y a las órdenes de los padres y de los cercos de vigilancia panópticos que se establecen entre ellos. 
El juego del marro es un instrumento diseñado por los adultos para adoctrinar a los jóvenes. En sí es un juego de niños, que nace de la propia voluntad de los adultos y de su disposición social. Los juegos de los niños son socializados para así también socializarlos a ellos. Pero además, con sus juegos participan de la emulación de la sociedad adulta y de las estrategias de ejercer la dominación. Se trata de un juego de transición hacia el comportamiento socializado, normativo, jerarquizado, de toma de decisiones y de riesgo de los adultos, de premios y de castigos, y de la aprensión de participar como dominadores o dominados.

Como citaba Guts Muths: "Los ejercicios gimnásticos son preparación necesaria para el futuro defensor de la patria y todo el mundo ha de ser defensor de la patria" (Diem 1966b: 245). El marro fue el juego que mejor reunió los requisitos deseados por higienistas, pedagogos, militares y moralistas religiosos de finales del siglo XVIII y principios del siglo XIX. Esta fue la principal razón de su éxito en toda Europa, y de que fuese presentado como un instrumento adecuado para ser sutilmente utilizado como ejercicio del poder de la "pedagogía burguesa" (Ballester y Colom 2015) sobre la infancia y la juventud. Este juego pues, como otros tantos juegos, se presentan como dispositivos de disciplinamiento que entran de lleno en lo que Foucault (1979: 104) llama la "microcirugía del poder" (un discurso del poder sin texto y discontinuo en el tiempo), una técnica de control social (de colonización lúdica de la infancia) ejercida de forma invisible y silenciosa por las instituciones (educativas, higiénicas, militares, religiosas...) «que conduce al deseo del propio cuerpo mediante un trabajo insistente, obstinado, meticuloso que el poder ha ejercido sobre el cuerpo de los niños, de los soldados, sobre el cuerpo sano".

Debemos pues, situar el ostrakinda como la base etnomotriz o el juego progenitor de los juegos de estrategia y, el marro, su evolución, constantemente renovado por los griegos, lo que dio asimismo origen a otros juegos parecidos (Mehl 1990; Pelegrín 1998; Solana 1943). Parece pues que podemos postular que el nombre de marro tiene sus orígenes en el juego de damas - y este en el ajedrez-. Sus características por lo que respecta a su lógica interna se asemejan a las del juego motriz, hecho por el cual se le dio el nombre de marro. El juego hoy continúa transformado en otra dimensión cuando subyace en el imaginario colectivo y este imaginario se hace virtual en el individuo. Son así los juegos de guerra — de fútbol— virtuales los que conservan la misma esencia agonística y simbólica del marro y manifiestan la evolución posmoderna del juego, a saber: todo un proceso de civilización.

Finalmente, nos queda referirnos a las limitaciones del presente estudio que solo ha hecho que empezar al abrir un espacio de discusión sobre este y otros juegos. Sobre el juego del marro todavía nos falta más imbricación con su permanencia geográfica y temporal en los diferentes territorios; así también el análisis de sus variantes locales, observando sus diferentes variantes estructurales de la lógica interna y las diferencias substanciales de la lógica externa. Por todo ello serán necesarios abordar otros estudios que también ayudarán a profundizar en el que aquí hemos presentado.

\section{BIBLIOGRAFÍA CITADA}

Agasse, Henry. 1797. Dictionnaire des jeux familiers. París: Agasse. 
Aguado, Francisco. 1641. Exhortaciones variadas, doctrinales. Madrid: Imp. de Francisco.

Alcocer, Francisco de. 1559. Tratado del juego. Salamanca: Andreas de Portonariis.

Allemagne, Henry-René. ca. 1903. Sports et jeux d'adresse. París: Hachette.

Álvarez, Eduardo. 1995. "La actividad físico-lúdica en el siglo de Oro español». Apunts: Educación Física y Deportes 4: 7-25.

Álvarez, Eduardo. 1999. "La educación física en la pedagogía humanista italiana e inglesa de los siglos XV y XVI". Apunts: Educación Física y Deportes 58: 14-24.

Amades, Joan. 1984. Auca dels jocs de la mainada. Barcelona: Altafulla.

Amar, Jean-Agustin y Louis François Jauffret. 1807. La gimnástica o escuela de la juventud, tratado elemental de juegos, de ejercicios considerados en razón de su utilidad física y moral. Madrid: Imp. Álvarez.

Andreu, Eliseo. 2009. "El juego infantil mediterráneo: Grecia antigua”. Aloma: Revista de Psicologia, Ciències de l'Educació $i$ de l'Esport 25: 39-51.

Andújar, Francisco. 2004. "El seminario de Nobles de Madrid en el siglo XVIII. Un Estudio social". Cuadernos de Historia Moderna. Anejos 3: 201-225.

Autoridades [Real Academia Española]. 1734. Diccionario de la lengua castellana IV. Madrid: Imp. de la Real Academia Española, Herederos de Francisco Hierro.

Ballester, Lluís y Antoni J. Colom. 2015. Walter Benjamin: Filosofía y pedagogía. Barcelona: Octaedro.

Bantulà, Jaume. 2005. "El joc popular i tradicional als segles XVI i XVII: revisió des d'una perspectiva taxonómica". Educació i Història 8: 134-146.

Bantulà, Jaume. 2006. "La introducció dels jocs populars i tradicionals en l'educació escolar dels infants". Temps d'Educació 8: 235-247.

Bantulà, Jaume y Conrad Vilanou. 2009. "Joc, humanisme i pedagogia: la virtut de l'eutrapèlia". Aloma 25: 53-89.

Bárcena, Fernando y Joan Carles Mélich. 2000. "Aprendizaje simbólico del cuerpo". Revista Complutense de Educación 11(2): 59-81.

Batista, Josep Maria. 1927. Manual d'excursionisme. Barcelona: Barcino.

Becq, Louis. 1869. Les Jeux des anciens. París: C. Reinwald.

Beleze, Guillaume. 1856. Jeux des adolescents. París: Lib. L. Hachette et C. ${ }^{2}$

Brasó, Jordi y Xavier Collell. 2016. "El joc popular de la Xarranca. Estudi a través dels llibres i del folklore català. Possibles aplicacions en l'àmbit escolar". REIRE. Revista d'Innovació i Recerca en Educació 9(2): 82-105.

Brasó, Jordi y Xavier Torrebadella. 2014. «El joc del rescat a Catalunya. Un projecte educatiu a l'Escola del Mar de Pere Vergés". Temps d'Educació 47: 167-184.

Brasó, Jordi y Xavier Torrebadella. 2015a. "Anàlisi i classificació dels jocs de la infància de Joan Amades en funció de la seva lògica interna i del gènere dels seus practicants (1674-1947)". REIRE. Revista d'Innovació i Recerca en Educació 8(2): 18-42.

Brasó, Jordi y Xavier Torrebadella. 2015b. "El joc del 'rescat' en el procés constituent de l'esport contemporani a Catalunya (1920-1926)". Aloma: Revista de Psicologia, Ciències de l'Educació $i$ de l'Esport 33(1): 79-91.

Brasó, Jordi y Xavier Torrebadella. 2015c. "El marro', un juego tradicional y popular en la educación física española (1807-1936)". Revista Complutense de Educación 26(3): 697-719.

Brunot-Labbe. 1812. Les écoliers en vacances. París: Brunot-Labbe.

Caillois, Roger. 1986. Los juegos y los hombres. La máscara y el vértigo. México: Fondo de Cultura Económica.

Calderón, José Manuel y Francisco Javier Díaz. 2011. "El rescate de prisioneros y cautivos durante la Edad Media Hispánica. Aproximación a su estudio". Historia, Instituciones y Documentos 38: 9-66.

Cambi, Franco y Gianfranco Staccioli. 2007. Il gioco in Occidente. Storia, teorie, pratiche. Roma: Armando Editore.

Caro, Rodrigo. 1884. Días geniales o lúdicros. Sevilla: Imp. de El Mercantil Sevillano.

Caro, Rodrigo. 1978. Días geniales o lúdicros. Madrid: Espasa Calpe [edición, estudio preliminar y notas de Jean-Pierre Etienvre].

Carver, Robin. 1834. The Book of Sports. Boston: Lilly, Wait, Colman and Holden. 
Castellanos, Basilio Sebastián. 1850. “Costumbres Españolas. De los juegos de los muchachos». Museo de los niños 4: 132-135.

Celmart. 1836. Manuel Complet des Jeux de Société. París: Lib. de Roret.

Chabreul. 1860. Jeux et exercicies des jeunes filles. París: Lib. L. Hachette et C. ${ }^{a}$

Clarke, William. 1829. The Boy's Own Book. Londres: Viztelly, Branston and Co.

Corriente, Federico y Jorge Montero. 2011. Citius, Altius, Fortius. El libro negro del deporte. Logroño: Pepitas de calabaza.

"Costumbres antiguas. Juegos de niños entre griegos y romanos". 1846. Semanario Pintoresco Español 1: 6. Covarrubias, Pedro. 1543. El Remedio de jugadores. Salamanca: Juan de Juntas.

Defauconpret, Auguste Jean-Baptiste. 1818. Anecdotes of the Court and Family of Napoleon Bonaparte. Londres: Impreso por H. Colburn.

Didron, Adolphe Napoleón. 1851. Annales archéologiques, vol. 11. París: Librairie Archéologique de Victor Didron.

Diem, Carl. 1966a. Historia de los deportes, vol. I. Barcelona: Luis de Caralt.

Diem, Carl. 1966b. Historia de los deportes, vol. II. Barcelona: Luis de Caralt.

Dunning, Eric. 2003. El fenómeno deportivo. Estudios sociológicos en torno al deporte, la violencia y la civilización. Barcelona: Paidotribo.

Elias, Norbert. 2010. El proceso de la civilización. Investigaciones sociogenéticas y psicogenéticas. Madrid: Fondo de Cultura Económica.

Elias, Norbert y Eric Dunning. 1992. Deporte y ocio en el proceso de civilización. Madrid: FCE.

Elliott, Alfred. 1868. The Playground and the Parlour: A Handbook of Boys' Games, Sports, and Amusements. Londres: T. Nelson and sons.

Elschenbroich, Donata. 1979. El juego de los niños. Estudios sobre la génesis de la infancia. Madrid: Zorro.

Fernández de los Ríos, Ángel. 1852. Los juegos en las diferentes edades en todos los pueblos del mundo desde la antigüedad más remota hasta nuestros días. Madrid: Biblioteca Universal.

Fleury. 1656. L'etymologie ou explication des proverbes françois. La Haya: Adrian Vlaco.

Flori, Jean. 2001. La caballería. Madrid: Alianza.

Foucault, Michel. 1979. Microfísica del poder. Madrid: La Piqueta.

Foucault, Michel. 2001. Los anormales. Madrid: Akal.

Foucault, Michel. 2012. Vigilar y Castigar. El Nacimiento de la prisión. Madrid: Biblioteca Nueva.

Friedlander, Michael. 1815. De l'éducation physique de l'home. París: Treuttel et Würtz.

García, José María. 1926. Manual de gimnasia para uso de los Exploradores Españoles. Madrid: Consejo Nacional de Exploradores de España.

Grasberger, Lorenz. 1864. Erziehung und Unterricht im klassischen Alterthum mit besonderer Rücksicht auf die Bedürfnisse der Gegenwart, vol. I. Würzurg: Druck und Verlag Stahel.

Graupera-Sanz, Jose Luis. 2010. "Semblanzas. Rodrigo Caro, precursor de la etnología de los juegos". RICYDE, International Journal of Sport Science 21: i-iv.

Griffin, Emma. 2005. England's Revelry: A History of Popular Sports and Pastimes, 1660-1830. Oxford: Oxford University Press.

Griffin, Roger. 2010. Modernismo y fascismo. La sensación de comienzo bajo Mussolini y Hitler. Madrid: Akal.

Guillemard, Gérard, Jean Claude Marchal, Martine Parent, Pierre Parlebas y André Schmitt. 1988. Las cuatro esquinas de los juegos. Lérida: Agonos.

Guts Muths, Johann Christoph. 1796. Spiele zur uebung und erholung des körpers und geistes, fur die jugend. Schnpfenthal: Im Verlage der Buchhandlung der Erziehungsanstalt.

Hervás, Lorenzo. 1798. Historia de la vida del hombre —Continuación de la parte II t. V. Imp. Madrid: Administración de la Rifa del Real Estudio de Medicina Práctica.

Hesse, José. 1967. El deporte en el siglo de oro. Madrid: Taurus.

Jentzer, Ketty. 1921. Juegos educativos al aire libre y en casa. Madrid: Librería Española y Extranjera y Editorial Beltrán.

Jeux des enfants. 1845. Le Magasin Pittoresque 40: 319-320.

Lavega, Pere y Vicente Navarro. 2015. "La motricidad en los juegos de Rodrigo Caro: días geniales o lúdicros (1626)". Revista Internacional de Medicina y Ciencias de la Actividad Física del Deporte 15(59): 489-505. 
Ledesma, Alonso de. 1611. Juegos de nochebuena moralizados a la vida de Christo, martirio de Santo y reformación de costumbres. Madrid: Alonso Martín.

Leibs, Andrew. 2004. Sports and Games of the Renaissance. Westport: Greenwood Publishing Group. Lillo, Fernando. 2004. Ludus. ¿Cómo jugar como los antiguos romanos? Madrid: Aurea.

Mandell, Richard. 1986. Historia Cultural del Deporte. Barcelona: Ed. Bellaterra.

Mariana, Juan de. 1845. Del rey y de la institución de la dignidad real. Madrid: Imp. de la Sociedad Literaria y Tipográfica.

Martínez, Anastasio. 1993. "Los valores de la naturaleza en la historia de la educación desde la óptica de la educación en el tiempo libre». Revista Complutense de Educación 4(1): 119-143.

Mehl, Jean-Michel. 1990. Les jeux au royaume de France du XIIT au XVI siècle. París: Fayard.

Mélich, Joan-Carles. 1994. Del extraño al cómplice. La educación en la vida cotidiana. Barcelona: Anthropos.

Montaigne, Michel de. 1887. Les essais. París: Librairie des Bibliophiles.

Mutel, Philippe. 1846. Higiene militar. Madrid: Lucas González y C. ${ }^{a}$

Nieremberg, Juan Eusebio. 1629. Las obras y dias, manual de señores y principes; en que se propone con su pureza y rigor la especulación y ejecución política, económica y particular de todas las virtudes. Madrid: Viuda de Alonso Martín.

Olod, Luis. 1766. Tratado del origen y arte de escribir bien. Gerona: Narciso Oliva.

Omeñaca, Raúl y Jesús Vicente Ruiz. 2003. Juegos cooperativos en educación física. Barcelona: Paidotribo.

Oudin, César. 1607. Thresor deux langues espagnolle et françoise. París: Marc Orry. Oudin.

Paredes, Jesús. 2002. El deporte como juego: un análisis cultural. Alicante: Universidad de Alicante. Parlebas, Pierre. 2001. Juegos, Deporte y Sociedad. Léxico de Praxiología Motriz. Barcelona: Paidotribo.

Pastor, José Luis. 1997. El espacio profesional de la educación Física en España: génesis y formación (1883-1961). Alcalá de Henares: Universidad de Alcalá de Henares.

Pavet de Courteille, Ch. 1827. Hygiène des colléges et des maisons d'éducatión des deux sexes. París: Jobard.

Pelegrín, Ana. 1998. Repertorio de antiguos juegos infantiles. Madrid: CSIC.

Pelegrín, Ana. 2000. "Juegos de aldeas y de la niñez en textos hispanos (1510-1820)", en Pilar IruretaGoyena (coord.), El juego en el libro antiguo: 23-52. Madrid: Universidad Politécnica de MadridINEF.

Perillán, Eloy. 1873. "Juegos”. El Periódico para todos 11: 168-170.

Piernavieja, Miguel. 1963. "Ideas del Padre Mariana sobre la educación física”. Citius, Altius, Fortius 5: $357-371$.

Pilot, M. J. J. A. 1841. Annuaire statistique de la Cour royale de Grenoble et du département de l'Isère. Grenoble: Chez Baratier Frères et Fils.

Pusalgas, Ignacio. 1831. Manual de higiene arreglado según la doctrina de sir John Sinclair. Barcelona: J. Rubio.

Rabelais, François. 2007. Gargantúa. Madrid: Akal.

Remón, Alonso. 1623. Entretenimientos y juegos honestos y recreaciones cristianas. Madrid: Viuda de Alonso Martín a costa de Lucas Ramírez.

Richardson, H. D. 1848. Holiday Sports and Pastimes for Boys. Londres: William S. Orr y Co.

Román, Jerónimo. 1595. Repúblicas del mundo. Medina del Campo: Francisco Canto.

Rosales, Jerónimo de. 1725. Caton Christiano y catecismo de la doctrina christiana: para la educación y buena crianza de los niños y provechoso para personas de todos estados. Barcelona: Bartolomé Giralt.

Salzmann, Christian Gotthilf [y Johann Christoph Guts Muths]. 1800. Gymnastics for Youth, or, a Practical Guide to Healthful and Amusing Exercises for the Use of Schools: An Essay toward the Necessary Improvement of Education, Chiefly as It Relates to the Body. Londres: J. Johnson.

Simon (de Metz). 1827. Traité d'hygiène appliquée à l'éducation de la jeunesse. París: Villeret.

Solana, Ezequiel. 1943. Curso completo de pedagogía. Primera parte. Madrid: El Misterio Español.

Spencer, Herbert. 1879. De la educación intelectual, moral y física. Sevilla: Imp. de R. Baldaraque.

Strutt, Joseph. 1801. The Sports and Pastime of People of England. Londres: Methuen y Co.

Suárez, Cristóbal. 1630. Plaza universal de todos ciencias y artes. Perpiñan: Luis Roure. 
Tissot, Samuel Auguste David. 1760. L'Onanisme: ou dissertation physique sur les maladies produites par la masturbation. Lausana: Chapuis.

Torrebadella, Xavier. 2011. "Vicente Naharro y los juegos corporales en la educación física española de la primera mitad del siglo XIX". Ágora para la Educación física 13(2): 165-182.

Torrebadella, Xavier. 2013. "La educación física y preámbulos deportivos en el contexto ilustrado y liberal de la primera Constitución española (1800-1814)». Rubrica Contemporanea 2(4): 73-99.

Torrebadella, Xavier y Miguel Vicente. 2016. "La gimnástica como dispositivo antionanista en la conformación de la educación física escolar en el siglo XIX en España. El nacimiento de una disciplina escolar". Movimento 22(1): 99-114.

Ulmann, Jacques. 1977. De la gymnastique aux sports modernes: histoire des doctrines de l'éducation physique. París: Vrin.

Uncle, John. 1851. The Boy's Book of Sports and Games: Containing Rules and Directions for the Practice of the Principal Recreative Amusements of Youth. Nueva York: D. Appleton y Co.

Valentine, Laura. 1867. The Home Book of Pleasure and Instruction. Londres: Frederick Warne.

Van Torre, Antonii. 1746. Dialogi familiares litterarum tironibus. Duaci: Willerval.

Varela, Julia. 1983. Modos de educación en la España de la Contrarreforma. Madrid: Ed. La Piqueta.

Varela, Julia. 1986. "Aproximación genealógica a la moderna percepción social de los niños". Revista de Educación 281: 155-175.

Varela, Julia. 2003. "Conocimiento, poder y subjetivación en las instituciones educativas. Sobre las potencialidades del método genealógico en el análisis de la educación formal e informal", en Thomas S. Popkewitz, Barry M. Franklin y Miguel Ángel Pereira (comps.), Historia cultural y educación: 127-145. Barcelona: Pomares.

Vázquez, Francisco y José Benito Seoane. 2004. «España y la cruzada médica contra la masturbación (1800-1900). Elementos para una genealogía». Hispania 218: 835-868.

Vigarello, Georges. 2005. Corregir el cuerpo. Historia de un poder pedagógico. Buenos Aires: Nueva Visión.

Walker, Donald. 1837. Games and Sports. Londres: Thomas Hurst.

Warne, Frederick (ed.). 1869. The Boy's Book of Sports, Games, Exercises and Pursuits. Londres: Fr. Warne and Co.

Westerveld, Govert. 2014. La reina Isabel la Católica: su reflejo en la dama poderosa de Valencia, cuna del ajedrez moderno y origen del juego de damas. España: Lulu.

Williams, Samuel y S. Gilbert Reuben. 1848. The Boy's Treasury of Sports, Pastimes, and Recreations. Boston: John P. Hill.

Fecha de recepción: 8 de octubre de 2015

Fecha de aprobación: 1 de agosto de 2016 